Artigo Original

\title{
Assessment of metabolic control among patients in a capillary glucose self-monitoring program
}

\author{
Avaliação do controle metabólico de pacientes de programa de automonitorização da glicemia capilar \\ Evaluación del control metabólico de pacientes de un programa de automonitorización de la glicemia capilar
}
Vivian Saraiva Veras ${ }^{1}$, Márcio Flávio Moura de Araújo ${ }^{2}$, Flávia Fernanda Luchetti Rodrigues $^{3}$, Manoel Antônio dos Santos ${ }^{4}$, Marta Maria Coelho Damasceno ${ }^{5}$, Maria Lúcia Zanetti ${ }^{6}$

\begin{abstract}
Objective: To assess the metabolic control of diabetes mellitus patients registered in a capillary glucose self-monitoring program at home. Methods: In this longitudinal retrospective study, 97 subjects at four health institutions in a Brazilian city were followed during 37 months between 2005 and 2008. The health files were analyzed of patients selected to register the evolution of variables related to capillary glucose self-monitoring at home and metabolic control of diabetes mellitus. Results: During the assessment, both mean and monthly percentages of capillary blood glucose measurements at home decreased from 34.1 (65.1\%) to 33.6 (64.8\%), respectively (p <0.001). Mean HbA1c levels dropped from $9.20 \%$ to $7.94 \%$ ( $\mathrm{p}<0.001)$. HDL cholesterol decreased from $51 \mathrm{mg} / \mathrm{dl}$ to $47 \mathrm{mg} / \mathrm{dl}$ ( $\mathrm{p}=0.001)$. Conclusion: Patients' metabolic control improved, characterized by a significant reduction in HbA1C.
\end{abstract}

Keywords: Diabetes mellitus; Blood glucose self-monitoring; Glucose

\section{RESUMO}

Objetivo: Avaliar o controle metabólico de pacientes com diabetes mellitus cadastrados em um programa de automonitorização da glicemia capilar no domicílio. Métodos: Estudo longitudinal retrospectivo que acompanhou 97 sujeitos de quatro instituições de saúde de cidade brasileira durante 37 meses entre os anos de 2005-2008. Foram analisados os prontuários de saúde dos pacientes selecionados para o registro da evolução de variáveis relacionadas à automonitorização da glicemia capilar no domicílio e o controle metabólico do diabetes mellitus. Resultados: Durante a avaliação tanto a média quanto o percentual mensal de medições da glicemia capilar em casa diminuiu de 34,1 (65,1\%) para 33,6 (64,8\%), respectivamente $(\mathrm{p}<0,001)$. O HDL colesterol diminuiu de $51 \mathrm{mg} / \mathrm{dl}$ para $47 \mathrm{mg} / \mathrm{dl}$ ( $\mathrm{p}=0.001)$ durante o período. Conclusão: Houve melhora do controle metabólico dos pacientes caracterizada pela redução significativa da HbA1C.

Descritores: Diabetes mellitus; Automonitorização da glicemia; Glicemia

\section{RESUMEN}

Objetivo: Evaluar el control metabólico de pacientes con diabetes mellitus registrados en un programa de automonitorización de la glicemia capilar en el domicilio. Métodos: Estudio longitudinal retrospectivo realizado con 97 sujetos de cuatro instituciones de salud de una ciudad brasileña durante 37 meses entre los años de 2005-2008. Se analizaron las historias clínicas de salud de los pacientes seleccionados para el registro de la evolución de variables relacionadas a la automonitorización de la glicemia capilar en el domicilio y el control metabólico de la diabetes mellitus. Resultados: Durante la evaluación tanto el promedio cuanto el porcentual mensual de mediciones de la glicemia capilar en casa disminuyó de 34,1 (65,1\%) a 33,6 (64,8\%), respectivamente ( $\mathrm{p}<0,001)$. El HDL colesterol disminuyó de $51 \mathrm{mg} / \mathrm{dl} \mathrm{a} 47 \mathrm{mg} / \mathrm{dl}$ ( $\mathrm{p}=0.001)$ durante el período. Conclusión: Hubo mejora del control metabólico de los pacientes caracterizada por la reducción significativa de la HbA1C.

Descrpitores: Diabetes mellitus; Automonitorización de la glucosa sanguínea; Glucemia

\footnotetext{
${ }^{1}$ MSc in Nursing. PhD. candidate, Graduate Nursing Program, Escola de Enfermagem de Ribeirão Preto, Universidade de São Paulo - USP - Ribeirão Preto (SP), Brazil.

${ }^{2}$ MSc in Nursing. PhD. candidate, Graduate Nursing Program, Universidade Federal do Ceará - UFC - Fortaleza (CE), Brazil. Assistant Professor I, Universidade Federal do Maranbão - UFMA - Imperatriz (MA), Brazil

${ }^{3}$ MSc in Nursing. Ph.D. candidate, Graduate Nursing Program, Faculdade de Enfermagem de Ribeirão Preto, Universidade de São Paulo - USP - Ribeirão Preto (SP), Brazil.

${ }^{4}$ PhD. in Clinical Psychology. Associate Professor, Faculdade de Filosofia Ciências e Letras, Universidade de São Paulo - Ribeirão Preto (SP), Brażil.

${ }^{5}$ PhD. in Nursing. Graduate Nursing Program, Universidade Federal do Ceará - UFC -Fortaleza (CE), Brazil.

${ }^{6}$ PhD. in Nursing. Associate Professor, Escola de Enfermagem de Ribeirão Preto, Universidade de São Paulo - Ribeirão Preto (SP), Braz̧il.
} 


\section{INTRODUCTION}

Capillary glucose self-monitoring (CGSM) is considered a part of diabetes mellitus (DM) interventions. It is fundamental to direct treatment actions as, based on the obtained results, the established treatment can be reassessed, adjusting insulin doses, diet and exercise. Besides, constructing a glycemic profile enhances knowledge on DM patients' attitudes, which can contribute to achieve acceptable metabolic control and, thus, prevent complications of the disease ( $(1,2)$.

The accomplishment of CGSM allows patients to cope with the disease independently. CGSM can also enhance a better understanding of the factors triggering the complications deriving from DM. This fact contributes to the improvement in quality of life, adhesion to medication therapy and motivation towards appropriate lifestyle changes ${ }^{(3)}$. CGSM results can be useful for hypoglycemia prevention, hypoglycemia and non-symptomatic hyperglycemia detection and in the adjustment of medication and non-medication therapeutic conduct for type 1 and type 2 DM patients. Only the recommended frequency varies, which should be defined based on each patient's individual needs and targets ${ }^{(1,4)}$.

Despite acknowledging CGSM as a fundamental part of treatment, however, it is known that many DM patients do not practice it for economic, social or psychological reasons ${ }^{(3,5)}$. Many health institutions that deliver care to DM patients still do not offer the materials needed for CGSM practice at home. This lack of coverage for such essential procedures for DM control is associated with other important barriers that need to be overcome with a view to successful glucose control stimulation strategies ${ }^{(3)}$.

Barriers for CGMS accomplishment may include health professionals and DM patients' lack of understanding about the importance of doing it and how to interpret the obtained results. Patients' lack of time and physical conditions and other factors can hamper CGSM ${ }^{(3,6-7)}$.

Studies support the conclusion that CGSM can help to enhance good metabolic control, when associated with diabetes education, which will support orientations to optimize the use of reactive strips and good handling of the glucometer and patient encouragement for lifestyle and behavioral changes in response to the CGSM results ${ }^{(8-11)}$. Other longitudinal studies, clinical trials and meta-analyses evidence that, in DM patients, CGSM is associated with achieving better glycated hemoglobin levels (HbA1c) ${ }^{(6,12,13)}$.

These studies support the American Diabetes Association (ADA) recommendations, which acknowledge that, in DM patients, whether using insulin or not,
CGSM is useful to reach glucose control goals, provided that the obtained levels are interpreted and followed by decision-making ${ }^{(2)}$.

An integrative literature review elaborated based on 28 papers found that publications on this theme are mostly elaborated in developed countries in North America (United States and Canada), Europe (United Kingdom, Denmark and Turkey), Asia (China) and Oceania (Australia). Besides, the services addressed in these studies are hospitals, schools and the subjects are children and adolescents with type $1 \mathrm{DM}$, gestational diabetes (GDM), elderly or blind people ${ }^{(14)}$. Thus, a lack of research on this theme is evidenced in Latin America and among primary healthcare patients.

In view of the above, the benefits for DM patients registered in home CGSM programs need to be assessed regarding improvements in their metabolic control. This kind of study can also provide important support to redirect primary care actions, considering the inputs offered for DM control. Thus, the goal of this paper was to assess the metabolic control of DM patients in a CGSM program at four health institutions in Ribeirão Preto, Brazil.

\section{METHODS}

This longitudinal, retrospective study was accomplished at four health institutions in Ribeirão Preto, Brazil, selected through convenience sampling, between November 2005 and December 2008.

The study population comprised 359 DM patients, attended at the health institutions and registered in the CGSM program at home. The system that controls the distribution of strategic materials to patients registered between November $1^{\text {st }} 2005$ and December $31^{\text {st }} 2008$ was consulted to obtain this number.

The following criteria were adopted to include study subjects: being a type 1 or $2 \mathrm{DM}$ patient, registered in the CGSM program, with self-completed worksheets for CGSM home records, participating in the program for at least six months; metabolic profile tests available in the health file (when starting to participate in the CGSM program and at least one measure after six months). In total, 262 patients were excluded, 100 due to the absence of home glucose profile worksheets at the beginning and at least six months after entering the program; 49 patient files were not located; 107 without metabolic profile test results in the health file before participating and/or at least six months after entering the program, five due to death and one dropped out of the program. The sample comprised $97 \mathrm{DM}$ patients who complied with the inclusion criteria.

For data collection, a form was elaborated with socio-demographic, clinical (diagnosis time, comor- 
bidities, currently used DM medication) and metabolic control (fasting plasma glucose, HbA1c, total cholesterol, triglycerides, LDL cholesterol, HDL cholesterol, systolic blood pressure [SBP] and diastolic blood pressure $[\mathrm{DBP}]$ of $\mathrm{DM}$ users) variables.

Five nurses collected the data, who participated in a 16-hour training program to guarantee data reliability. A pilot test was developed in March 2009, using ten worksheets. The information collected in this phase was not included in the final study.

For data collection, the selected subjects' files were analyzed, stored in the health institution's medical archives. For each research variable, the collected data referred to the start of the program and at least one measure after having participated in the CGSM program for six months. Data were collected between February and June 2009.

The following reference levels were considered in the analysis of metabolic control parameters: plasma glucose $(70-130 \mathrm{mg} / \mathrm{dl})$; HbA1c $(\leq 7.0 \%)$; total cholesterol $(<200 \mathrm{mg} / \mathrm{dl})$; triglycerides $(\leq 150 \mathrm{mg} / \mathrm{dl}) ; \mathrm{LDL}$ $(\leq 100 \mathrm{mg} / \mathrm{dl}) ; \mathrm{HDL}(>50 \mathrm{mg} / \mathrm{dl}) ; \mathrm{SBP}(<130 \mathrm{mmHg})$ and DBP $(<80 \mathrm{mmHg})^{(2)}$

The obtained information was organized in a Microsoft XP Excel worksheet through double entry, followed by validation. Descriptive and inferential statistics were used for data analysis. To check for difference in results between the preset periods, Student's paired T-test was used. The PROC TEST procedure in SAS ${ }^{\circledR} 9.0$ software was applied to develop this analysis. The observed differences were considered significant at $\mathrm{p}<0.05$.

Approval for the project was obtained from the Institutional Review Board at the University of São Paulo at Ribeirão Preto College of Nursing, under protocol No. 0866/2007.

\section{RESULTS}

Among the research subjects (97), the majority was female (73.2\%), between 10 and 92 years of age. The predominant age range varied between 60 and 69 years $(32 \%)$. DM diagnosis time ranged from 2 to 28 years, $54.2 \%$ of the subjects suffered from arterial hypertension and $22.8 \%$ arterial hypertension and dyslipidemia. Approximately half of the subjects, $53.6 \%$, used oral antidiabetics (Biguanides) associated with insulin (53.6\%); $19.6 \%$ insulin only and $17.5 \%$, oral diabetics (Biguanides and Sulfonylureas) associated with insulin for glucose control. The majority (82.4\%) was under follow-up for DM control at health institutions.

During the assessment, the means and monthly CGSM percentages dropped from $34.1(65.1 \%)$ to $33.6(64.8 \%)$, respectively $(\mathrm{p}<0.001)$. The number of tests prescribed per day to do capillary blood glucose monitoring at home was from two to four tests, mean of two tests per day. It is highlighted that contact with the health professional (pharmacist) was conducted monthly during the delivery of the worksheets completed by the patient to acquiring the reagent strips. The control of the number of distributed strips occurred through the delivery of monthly spreadsheets, which were properly completed. On the other hand, there was no systematic conference of the values in the spreadsheet with those in the blood glucose monitor memory.

The number of reagent strips for CGSM at home that is offered per month to registered DM patients varied between 50 and 120 per month, with a mean number of $52.0(\mathrm{SD} \pm 10.4)$ and median 50 strips, respectively.

The association between the number of capillary glucose measures and gender revealed that, at the start of their participation in the CGSM program, the mean number of glucose measures for women, (36.2/SD \pm 17.5$)$, was higher than that of men, (28.1/ $\mathrm{SD} \pm 14.6)$ and statistically significant $(p=0.029)$. Regarding the association between the number of capillary glucose measures in one month, age and education level, no statistically significant correlation was verified during the research period.

As for fasting plasma glucose levels, this data was present in only 95 subjects' files. A slight reduction in mean levels was found, from $185 \mathrm{mg} / \mathrm{dl}$ to $172 \mathrm{mg} /$ $\mathrm{dl}$, during the research period, but without statistical significance $(\mathrm{p}=0.246)$. Also, the mean HbA1c levels dropped from $9.20 \%$ to $7.94 \%(p<0.001)$. On the other hand, no HbA1c levels were registered in the files of $28.9 \%$ and $55.7 \%$ before and after their participation in the program, respectively (Table 1).

With regard to total cholesterol, the number of subjects with excellent levels $(<200 \mathrm{mg} / \mathrm{dl})$ increased by $15.3 \%$, while individuals with bad levels $(\geq 240 \mathrm{mg} /$ dl) dropped by $20.1 \%$ during their participation in the program. Regarding LDL-C, the lack of records in the patient files before $(79.5 \%)$ and after $(82.5 \%)$ the subjects' entry into the CGSM program at home made more detailed data analysis impossible. As for HDL-C, a statistically significant drop from $51 \mathrm{mg} / \mathrm{dl}$ to $47 \mathrm{mg} /$ $\mathrm{dl}(\mathrm{p}=0.001)$ was observed. No statistically significant difference was found between triglyceride levels before and after the subjects' inclusion in the CGSM program at home (Table 1).

After having participating in the CGSM program for at least six months, the mean (SBP/DBP) dropped from $136 \mathrm{mmHg} / 82 \mathrm{mmHg}$ to $132.8 \mathrm{mmHg} / 80.2$ $\mathrm{mmHg}$, but without statistical significance $(\mathrm{p}=0.276$ and $\mathrm{p}=0.200$, respectively) (Table 1 ). 
Table 1. Distribution of diabetes mellitus patients registered in the CGSM program at home according to metabolic control variables at the start and after participating in the program for at least six months. Ribeirão Preto, Brazil, 2009

\begin{tabular}{|c|c|c|c|c|c|c|c|c|}
\hline Variables & Comparisons & $\mathbf{N}$ & Means & Differences & CI $(95 \%)$ & gl & $\mathbf{t}$ & p-value \\
\hline \multirow{2}{*}{ Fasting Glucose } & Before & 95 & 185.11 & \multirow{2}{*}{13.07} & \multirow{2}{*}{$(-9.16 ; 35.31)$} & \multirow{2}{*}{94} & \multirow{2}{*}{1.17} & \multirow{2}{*}{0.246} \\
\hline & After & 95 & 172.03 & & & & & \\
\hline \multirow{2}{*}{$\mathrm{Hb} 1 \mathrm{ac}$} & Before & 40 & 9.20 & \multirow{2}{*}{1.26} & \multirow{2}{*}{$(0.72 ; 1.79)$} & \multirow{2}{*}{39} & \multirow{2}{*}{4.79} & \multirow{2}{*}{$<0.001^{*}$} \\
\hline & After & 40 & 7.94 & & & & & \\
\hline \multirow{2}{*}{ Total Cholesterol } & Before & 92 & 209.27 & \multirow{2}{*}{5.23} & \multirow{2}{*}{$(-16.65 ; 27.12)$} & \multirow{2}{*}{91} & \multirow{2}{*}{0.48} & \multirow{2}{*}{0.635} \\
\hline & After & 92 & 204.03 & & & & & \\
\hline \multirow{2}{*}{ LDL-C } & Before & 6 & 130,47 & \multirow{2}{*}{-16.30} & \multirow{2}{*}{$(-48.61 ; 16.01)$} & \multirow{2}{*}{5} & \multirow{2}{*}{-1.30} & \multirow{2}{*}{0.251} \\
\hline & After & 6 & 146.77 & & & & & \\
\hline \multirow{2}{*}{ HDL-C } & Before & 65 & 51.26 & \multirow{2}{*}{3.38} & \multirow{2}{*}{$(0.73 ; 6.03)$} & \multirow{2}{*}{64} & \multirow{2}{*}{2.55} & \multirow{2}{*}{0.013} \\
\hline & After & 65 & 47.88 & & & & & \\
\hline \multirow{2}{*}{ Triglycerides } & Before & 88 & 212.59 & \multirow{2}{*}{16.99} & \multirow{2}{*}{$(-39.80 ; 73.77)$} & \multirow{2}{*}{87} & \multirow{2}{*}{0.59} & \multirow{2}{*}{0.553} \\
\hline & After & 88 & 195.60 & & & & & \\
\hline SRD & Before & 97 & 136.19 & 200 & 100 & & & \\
\hline & After & 97 & 132.89 & (5) & $(-2.00,9.20)$ & 然 & 1.07 & 0.270 \\
\hline & Before & 97 & 82.06 & & & & & \\
\hline DDI & After & 97 & 80.21 & 1.03 & $(-0.9), 4.1$ & 30 & 1.29 & 0.200 \\
\hline
\end{tabular}

$*_{\mathrm{p}}<0.001$ for Student's T-test for paired samples.

\section{DISCUSSION}

In this study, a statistically significant reduction in $\mathrm{HbA}_{1} \mathrm{C}$ was detected in the research sample. No consensus exists yet in literature about the association between CGSM practice and decreases in $\mathrm{HbA}_{1} \mathrm{C}$ levels. Most of the longitudinal and/or experimental studies found, coming from countries like Germany, Austria, United States, Japan, Great Britain, Italy, Brazil and Russia, sustain that CGSM at home is related with a drop in $\mathrm{HbA}_{1} \mathrm{C}$, and consequently with better metabolic control of $\mathrm{DM}^{(4,5,11,15-17)}$. Research has been developed in France, the United States and Great Britain, however, in which no significant differences were detected in the abovementioned association ${ }^{(18-20)}$.

Reducing $\mathrm{HbA}_{1} \mathrm{C}$ in $\mathrm{DM} 1$ or 2 patients is important as each percentage point increase in $\mathrm{HbA}_{1} \mathrm{C}$ entails a relative risk of 1.15 and 1.32 in subjects with DM 1 , and 1.18 and 1.28 for DM2 patients, for coronary and peripheral heart disease ${ }^{(10,12)}$. Hence, considering its applicability, this test should be requested as a part of routine, twice per year for all DM patients and four times per year for patients whose therapeutic scheme changed or who are not reaching the recommended objectives through the current treatment ${ }^{(2,12)}$.
In this study, despite regular medical monitoring, most DM users under analysis showed a statistically significant decrease in HDL cholesterol. Patients, especially DM2 patients, suffer from abnormalities in lipid and plasma lipoprotein concentrations, increasing these subjects' cardiovascular risk ${ }^{(2,12)}$. Hence, it is important for these patients to know how to interpret their glucose levels, as this can contribute to change their lifestyles and, consequently, mitigate their lipid profile.

In the research sample, CGSM significantly decreased over time. The ideal CGSM frequency remains a source of contradiction. The ADA, for example, recommends that the frequency of CGSM at home should take into account individual needs to achieve satisfactory glucose and metabolic control ${ }^{(2)}$. Other studies, in turn, found that good glycemic control does not depend on the type or frequency of CGSM at home and that, over time, the improvements achieved in glucose levels, using any kind of monitoring, tend to worsen without the health team's monitoring, intensive attention to and involvement with DM patients ${ }^{(17,21,22)}$.

The main barriers raised for CGSM, found in previous publications, are the pain the procedure causes, lack of skill to handle the glucometer and the cost of reagent strips ${ }^{(22,23)}$. Therefore, health professionals should also 
use their competences and skills to train DM patients to correctly and painlessly monitor their glucose. A good start in this sense would be the adoption of home visits for orientations about these techniques, which would culminate in greater adherence to CGSM.

In this research, CGSM practice was more frequent among women before the start of the CGSM program. In a literature review, no Brazilian or international studies were found about the association between the number of capillary glucose measures and gender. Nevertheless, women experience more difficulties to put in practice DM metabolic control actions, such as a balanced diet and regular physical exercise ${ }^{(24)}$.

Thus, subjects who practice CGSM need continuous health education, involving a multiprofessional team, which takes into account patients' individuality and daily reality, as well as gender and age variables in the accomplishment of this procedure.

CGSM is an essential resource for good control among DM patients, provided that it is used coherently, with cost effectiveness and using the specifically indicated test frequency for each clinical condition. The main criticism manifested in some publications is patients' difficulty to make decisions in view of CGSM results at home. In fact, without adequate diabetes education and practical orientation on what to do with the test results, CGSM at home offers more harm than benefits to the health system ${ }^{(12,25,26)}$.

The results obtained in this study show that the implementation of the CGSM program at home improved DM patients' metabolic control regarding $\mathrm{HbA}_{1} \mathrm{C}$. For the program to achieve excellence and address the other metabolic control parameters, an educative program needs to be set up for patients and health professionals. Patients need training on how to use the glucometers, understand the reasons justifying the times when tests are due, interpret the glucose results and acknowledge when action is needed as a result of glucose levels.

\section{REFERENCES}

1. Saudek CD, Derr, RL. Kalyani RR. Assessing Glycemia in Diabetes Using Self-Monitoring Blood Glucose and Hemoglobin A1c. JAMA. 2006; 295(14):1688-97.

2. American Diabetes Association. Standards of Medical Care in Diabetes - 2008. Diabetes Care. 2008; 31(Suppl1):S12-54.

3. Wang P, Lau J, Chalmers TC. Meta-analysis of effects of intensive blood glucose control on late complications of type I diabetes. Lancet. 1993; 341(8856):1306-9.

4. Grossi SA, Lottenberg SA, Lottenberg AM, Della Manna T, Kuperman H. Home blood glucose monitoring in type 1 diabetes mellitus. Rev Latinoam Enferm. 2009; 17(2): 194-200.

5. Starostina EG, Antsiferov M, Galstyan, GR, Trautner C, Jörgens V, Bott U, et al. Effectiveness and cost-benefit analysis of intensive treatment and teaching programmes for type 1 (insulin-dependent) diabetes mellitus in Moscow - blood
Some limitations were met in the development of this study, including the absence of records in health files and program abandonment rates, hampering a more accurate global view of DM patients' metabolic control.

\section{CONCLUSION}

The results showed that, despite the significant drop in $\mathrm{HbA}_{1} \mathrm{C}$, lipid profile levels still are not in accordance with the normality parameters the main DM care and research entities recommend, evidencing the complexity of patient care. Nevertheless, the clinical importance of CGSM at home needs to be taken into account, which can lead to the self-accountability and empowerment of DM patients for their self-care.

In Brazil, oral antidiabetics, insulin, syringes and needles are already distributed for free all over the country, but the supply of reagent strips and glucometers, unfortunately, is still restricted to some specialized health services. Therefore, this right should be expanded to all DM patients in the country. For patients with access to CGSM material at home, it should be emphasized that this action alone does not improve glucose control without decision making based on the obtained results. DM patients need orientation on the times to check capillary glucose throughout the day, and need to acknowledge levels beyond the established targets. In view of the obtained levels, they should learn to take effective measures in order to improve their metabolic control.

In view of the positive results of CGSM for $\mathrm{HbA}_{1} \mathrm{c}$ in the research sample, this research model could be replicated in other Brazilian locations and other countries, with a view to building a more reliable epidemiological picture on this theme. This action can certainly raise awareness and encourage the elaboration of public health policies that culminate in the expansion of materials for CGSM and health promotion of DM patients.

glucose versus urine glucose selfmonitoring. Diabetologia. 1994; 37(2): 170-6.

6. Karter AJ, Ferrara A, Darbinian JA, Ackerson LM, Selby JV. Self-monitoring of blood glucose: language and financial barriers in a managed care population with diabetes. Diabetes Care. 2000; 23(4): 477-83.

7. Karter AJ, Ackerson LM. Self-monitoring of blood glucose levels and glycemic control: the Northern California Kaiser Permanente Diabetes registry. Am J Med. 2001; 111(1):1-9.

8. The effect of intensive treatment of diabetes on the development and progression of long-term complication in insulin dependent diabetes mellitus. Diabetes Control and Complications Trial Research Group-DCCT. N England J Med. 1993; 329(14):977-86.

9. Intensive blood-glucose control with sulfonylureas or insulin compared with conventional treatment and risk of 
complications in patients with type 2 diabetes (UKPDS 33). UK Prospective Diabetes Study Group. Lancet. 1998; 352(9131): 837-53.

10. Selvin E, Marinopoulos S, Berkenblit G, Rami T, Brancati FL, Powe NR, et al. Meta-analysis: glycosylated hemoglobin and cardiovascular disease in diabetes mellitus. Ann Intern Med. 2004; 141(6):421-31.

11. Franciosi M, Pellegrini F, De Berradis G, Belfiglio M, Di Nardo B, Greenfield F, et al. Self-monitoring of blood glucose in non-insulin-treated diabetic patients: a longitudinal evaluation of its impact on metabolic control. Diabet Med. 2005; 22(7): 900-6.

12. Sociedade Brasileira de Diabetes. Diretrizes da Sociedade Brasileira de Diabetes. São Paulo: SBD; 2008.108 p.

13. Ryden L, Standl E, Bartnik M, Berghe GV, Betteridge, J, Boer, MJ, et al. Guidelines on diabetes, pré-diabetes, and cardiovascular dsease. Eur Heart J. 2007; 28(1): 88-136. Comment in: Eur Heart J. 2007;28(11):1401-2; author reply 1402.

14. Teixeira CR, Zanetti ML, Landim CA, Becker TA, Santos EC, Franco RC, Citro R. [Self-monitoring blood glucose at home: integrative literature review]. Rev Eletronica Enferm [Internet]. 2009; 11(4): 1006-17. [Portuguese]. Available from: http:// www.fen.ufg.br/revista/v11/n4/v11n4a27.htm.

15. Schwedes U, Siebolds M, Mertes G. Meal-related structured self-monitoring of blood glucose: effect on diabetes control in non-insulin-treated type 2 diabetic patients. Diabetes Care. 2002; 25(11):1928-32.

16. Ohkubo Y, Kishikawa H, Araki E, Miyata T, Isami S, Motoyoshi S, et al. Intensive insulin therapy prevents the progression of diabetic microvascular complications in Japanese patients with non-insulin-dependent diabetes mellitus: a randomized prospective 6-year study. Diabetes Res Clin Pract .1995; 28(6):103-17.

17. Davidson MB, Castellanos M, Kain D, Duran P. The effect of self monitoring of blood glucose concentrations on glycated hemoglobin levels in diabetic patients not taking insulin: a blinded, randomized trial. Am J Med. 2005; 118(4): 422-5.
Comment in: Am J Med. 2005;118(12):1448; author reply 1448-9; Am J Med. 2006;119(2):186; author reply 186.

18. Fontbonne A, Billault B, Acosta M, Percheron C, Varenne P, Besse A, et al. Is glucose self-monitoring beneficial in noninsulin-treated diabetic patients? Results of a randomized comparative trial. Diabete Metab. 1989; 15(5): 255-60.

19. Davis WA, Bruce DG, Davis TM. Is Self-monitoring of blood glucose appropriate for all type 2 diabetic patients? The Fremantle Diabetes Study. Diabetes Care. 2006; 29(8):1764-70.

20. Farmer AJ, Wade AN, French DP, Simon J, Yudkin P, Gray A, Craven A, Goyder L, Holman RR, Mant D, Kinmonth AL, Neil HA; DiGEM Trial Group. Blood glucose selfmonitoring in type 2 diabetes: a randomised controlled trial. Health Technol Asses. 2009; 13(15): iii-iv, ix-xi, 1-50.

21. Schütt M, Kern W, Krause U, Busch P, Dapp A, Grziwotz R, et al. Is the frequency of self-monitoring of blood glucose related to long-term metabolic control? Multicenter analysis including 24,500 patients from 191 centers in Germany and Austria. Exp Clin Endocrinol Diabetes. 2006; 114(7): 384-8.

22. Ziegler R, Heidtmann B, Hilgard D, Hofer S, Rosenbauer J, Holl R. Frequency of SMBG correlates with HbA1c and acute complications in children and adolescents with type 1 diabetes. Pediatr Diabetes. 2011; 12(1):11-7.

23. Dalewitz JB, Khan NM, Hershey CO. Barriers to control of blood glucose in diabetes mellitus. Am J Med Qual. 2000; 15(1): 16-24.

24. Péres DS, Franco LJ, dos Santos MA. [Eating behavior among type 2 diabetes women]. Rev Saúde Pública. 2006; 40(2): 310-7. Portuguese.

25. Mcintosh B, Yu C, Lal A, Chelak K, Cameron C, Singh SR, et al. Efficacy of self-monitoring of blood glucose in patients with type 2 diabetes mellitus managed without insulin: a systematic review and meta-analysis. Open Med. 2010; 4(2):102-13.

26. Kleefstra N, Hortensius J, van Hateren KJ, Logtenberg SJ, Houweling ST, Gans RO, et al. Self-monitoring of blood glucose in noninsulin-treated type 2 diabetes: an overview. Diabetes Metab Syndr Obes. 2009; 2:155-63. 